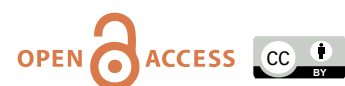

doi: $10.31729 /$ jnma.6324

\title{
Type I Lip Pattern in at Least One Quadrant among First and Second- year Medical and Dental Students of a Medical College: A Descriptive Cross-sectional Study
}

\author{
Sarbada Makaju, ${ }^{1}$ Sonam Chaudhary, ${ }^{2}$ Chandra Kala Rai ${ }^{3}$ \\ 'Department of Anatomy, Kathmandu Medical College and Teaching Hospital, Duwakot, Bhaktapur, Nepal, \\ ${ }^{2}$ Department of Physiology, Institute of Medicine, Maharguni, Kathmandu, Nepal, ${ }^{3}$ Department of Physiology, \\ Kathmandu Medical College and Teaching Hospital, Duwakot, Bhaktapur, Nepal.
}

\section{ABSTRACT}

Introduction: The upper and lower lip consists of the numerous amounts of fine grooves. This pattern of grooves will be definite throughout the lifetime. The groove of the lip shows variations and play important role in forensic medicine and crime investigation. The objective of this study is to find out the prevalence of type I lip print in at least one lip quadrant among first- and second- year medical and dental students of a medical college.

Methods: The study was conducted on 240 students of a medical college between November 2020 January 2021 after getting the ethical clearance from the Institutional Review Committee (reference no. KMC-IRC 0311202006). The convenient sampling was done. The patterns of the grooves of the lip were studied. The data was analysed with Statistical Package for the Social Sciences 20 version. Point estimate at $95 \%$ Confidence Interval was calculated along with frequency and percentage for binary data.

Results: Out of 240 students, type I lip pattern was seen in at least one quadrant in 190 (79.6\%) (73.3884.94 at $95 \% \mathrm{CI})$ students. One hundred and fifty-nine $(66.3 \%)$ had type I pattern in the right upper quadrant, $160(66.7 \%)$ in left upper quadrant, 181 (75.4\%) in right lower quadrant, and $177(73.8 \%)$ in left lower quadrant. Type Ia was maximum found in 115 (47.9\%) and type $\mathrm{Ib}$ in 66 (27.5\%) in lower left quadrant of lip.

Conclusions: Our findings showed a higher prevalence of type I lip pattern than those reported by other national studies done among medical students.

Keywords: grooves; identification; lips; patterns.

\section{INTRODUCTION}

The lips are considered as an essential aspect of the human face. The lips functions are mastication, phonation, facial expression, physical attraction and also intimacy. In the medical terms, the upper and lower lips are known as labium superioris and labium inferioris respectively. ${ }^{1}$ Both the upper and lower lip consists of large amount of the mucous gland. Both the lips consist of the numerous amounts of grooves. The study of lip prints is called cheiloscopy. ${ }^{2}$

The fingerprints are widely used as an identifications aid. However, lip prints can be an additional tool for identification and during crime investigation. ${ }^{3}$ Studies from our settings can be valuable in providing data about the most common types of lip prints.

The aim of this study is to find out the prevalence of type I lip pattern among first- and second-year medical and dental students of a medical college.

\section{METHODS}

The descriptive cross-sectional study was carried out in Kathmandu Medical College and Teaching Hospital in

Correspondence: Dr. Sarbada Makaju, Department of Anatomy, Kathmandu Medical College and Teaching Hospital, Duwakot, Bhaktapur, Nepal. Email: sarbadamakaju@gmail.com, Phone: +977-9846119330. 
between November 2020 to January 2021 after getting the ethical clearance from the Institutional Review Committee (reference number- KMC-IRC 0311202006). All the medical and dental students of first and second years were included. Any history of surgery, trauma and ulcers on the lip were excluded. Participants were enrolled using convenient sampling and the sample size was calculated as:

$$
\begin{aligned}
\mathrm{n} & =\mathrm{Z}^{2} \times \mathrm{p} \times(1-\mathrm{p}) / \mathrm{e}^{2} \\
& =(1.96)^{2} \times(0.50) \times(1-0.50) /(0.04)^{2} \\
& =601
\end{aligned}
$$

The sample size was adjusted for finite population as, $\mathrm{no}=(\mathrm{nN}) /[\mathrm{N}+(\mathrm{n}-1)]$

$$
\begin{aligned}
& =(601 \times 300) /[300+(601-1) \\
& =201
\end{aligned}
$$

where,

$\mathrm{n}=$ minimum required sample size for infinite population

$\mathrm{Z}=\mathbf{1 . 9 6}$ at $95 \%$ Confidence Interval $(\mathrm{Cl})$

$\mathrm{p}=$ past prevalence taken as $50 \%$ for maximum sample size

$\mathrm{e}=$ margin of error, $4 \%$

$\mathrm{n}_{\mathrm{o}}=$ adjusted sample size for finite population

$\mathrm{N}=$ total number of first- and second-year medical and dental students $=300$

Taking a $10 \%$ non-response rate, the sample size became 221. However, 240 participants were enrolled in the study.

The participations were included after taking verbal informed consent among the students in Kathmandu Medical College and Teaching Hospital between 1820 years by using convenient sampling. The lips were wiped with the cotton properly inorder to remove the debris. And the dark red coloured lipstick was applied to the lips. Allow the lipstick immersed all over the vermillion borders of the lips. Then the cello tape was put over the lips. And the impression of lip in cello tape was pasted in the white A4 size paper. Then a lens was used to see the grooves of lip. The lips were divided into the four quadrants and the study was done respectively. The classification of patterns of the lines on the lips was done as proposed by TsuchihashiY.,6

Type la: Clear-cut vertical groove that run across the entire lips.

Type Ib: Similar to type I, but do not cover the entire lip

Type II: Branched grooves (branching $Y$-shaped pattern)

Type III: Cross/intersected

Type IV: Reticular grooves

Type V- Undetermined
The data obtained was analysed with Statistical Package for the Social Sciences 20 version using descriptive statistics. Point estimate at $95 \% \mathrm{Cl}$ was calculated along with frequency and proportion for binary data.

\section{RESULTS}

In this study, 190 (79.16\%) (73.38-84.94 at 95\% Cl) students had type I print in at least one quadrant of their lips. Out of the four quadrants, left lower quadrant showed the maximum Type 1 in 181 (75.4\%) (Figure 1).

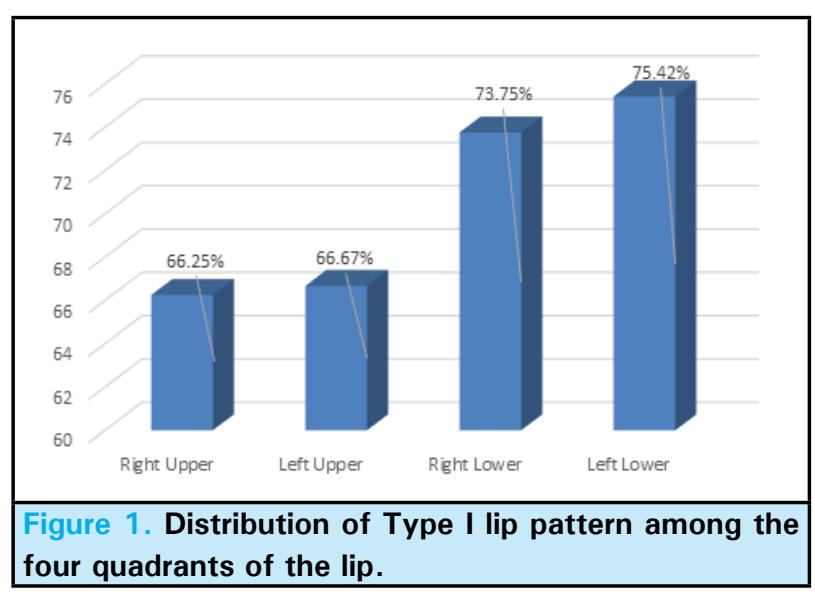

One hundred and fifty-nine (66.3\%) had type I pattern in the right upper quadrant (RUQ), 160 (66.7\%) in left upper quadrant (LUQ), 177 (73.8\%) in right lower quadrant (RLQ), and $181(75.4 \%)$ in left lower quadrant (LLQ). The maximum Type la was found in 115 (47.9\%) and type $\mathrm{Ib}$ in $66(27.5 \%)$ in at least one quadrant of the lip (Table 1).

\begin{tabular}{|lllll|}
\hline \multicolumn{4}{|l}{ Table 1. Distribution of Type I lip pattern among four } \\
quadrants of the lip. \\
\hline Types & Right & Left & Right & Left \\
& Upper & Upper & Lower & Lower \\
& Quadrant & Quadrant & Quadrant & Quadrant \\
& $\mathrm{n}(\%)$ & $\mathrm{n}(\%)$ & $\mathrm{n}(\%)$ & $\mathrm{n}(\%)$ \\
Type I & $159(66.3)$ & $160(66.7)$ & $177(73.8)$ & $181(75.4)$ \\
Type la & $97(40.4)$ & $99(41.3)$ & $113(47.1)$ & $115(47.9)$ \\
Type Ib & $62(25.8)$ & $61(25.4)$ & $64(26.7)$ & $66(27.5)$ \\
\hline
\end{tabular}

Our study showed that type I was the most prevalent lip pattern in both the genders. Type la was most common in females as $83(34.5 \%)$ had type la in $R U Q$, 84 (35\%) in LUQ, 79 (32.91\%) in RLQ, and 79 (32.91\%) in LLQ. Type lb was more common in males as 45 (18.7\%) had type Ib in RUQ, 45 (18.7\%) in LUQ, 44 $(18.3 \%)$ in RLQ, and $46(19.16 \%)$ in LLQ respectively. Type $\mathrm{V}$ pattern was not found in our study. The second most common type was Type III in the upper lip in 67 (27.92\%) and Type II in the lower lip in 60 (25\%). Type IV was the least common pattern (Table 2). 
Makaju et al. Type I Lip Pattern in at Least One Quadrant among First and Second-year Medical Students...

\begin{tabular}{|c|c|c|c|c|c|c|c|c|}
\hline \multirow[t]{3}{*}{$\begin{array}{l}\text { Lip } \\
\text { pattern }\end{array}$} & \multicolumn{2}{|c|}{ Right Upper Quadrant } & \multicolumn{2}{|c|}{ Left Upper Quadrant } & \multicolumn{2}{|c|}{$\begin{array}{l}\text { Right Lower } \\
\text { Quadrant }\end{array}$} & \multicolumn{2}{|c|}{ Left Lower Quadrant } \\
\hline & Male & Female & Male & Female & Male & Female & Male & Female \\
\hline & n (\%) & n (\%) & n (\%) & n (\%) & n (\%) & n (\%) & n (\%) & n (\%) \\
\hline Type la & $14(5.8)$ & 83 (34.5) & $15(6.25)$ & $84(35)$ & $34(14.16)$ & 79 (32.91) & 36 (15) & 79 (32.91) \\
\hline Type Ib & 45 (18.75) & $17(7.08)$ & 45 (18.75) & $16(6.6)$ & 44 (18.33) & $20(8.3)$ & 46 (19.16) & $20(8.3)$ \\
\hline Type II & $13(5.4)$ & $13(5.41)$ & $13(5.4)$ & $13(5.41)$ & $16(6.6)$ & $15(6.25)$ & $14(5.83)$ & $15(6.25)$ \\
\hline Type III & $28(11.6)$ & $6(2.5)$ & 27 (11.25) & $6(2.5)$ & $17(7.08)$ & $5(2.08)$ & $17(7.08)$ & $5(2.08)$ \\
\hline Type IV & $20(8.3)$ & $1(0.41)$ & $20(8.3)$ & $1(0.41)$ & $9(3.75)$ & $1(0.41)$ & $7(2.91)$ & $1(0.41)$ \\
\hline
\end{tabular}

In this study, Type $\mathrm{V}$ was not determined in any quadrant of lip. The least types of lip pattern found in this study was Type IV in all the four quadrants of the lip. It was seen in $21(8.8 \%)$ in the RUQ, $21(8.8 \%)$ in the LUQ, $8(3.5 \%)$ in the LLQ, and $10(4.2 \%)$ in the RLO (Figure 2).

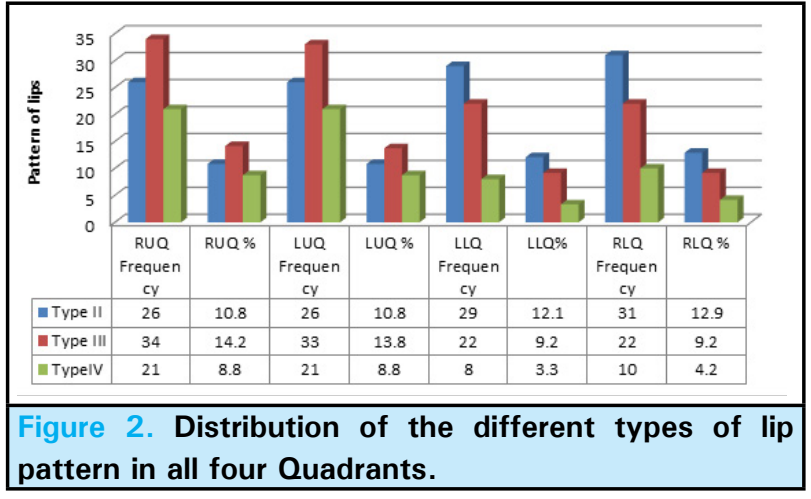

\section{DISCUSSION}

The lip prints are the permanent fold present in the entire life. In the world of forensic science there are various aid is used for personal identification. Nowadays, the lip prints are also used for aid of identification. During the crime investigation, the lip print can be visible or not in an object, If it is not visible lip prints can be developed by using various dyes and methods. The impressions can be collected and interpreted according to the above classification. ${ }^{5,6}$

In this study, Type $V$ was not found in the sample. In all the quadrants of the lip Type la was commonest and the Type Ib was the second one respectively. Whereas in the comparisons to other Types, Type IV was the least. Whereas in the four quadrants of lip, Type la was common in lower left and lower right respectively. In the entire quadrant Type IV was minimum. This finding was supported by S Gurung ${ }^{7}$ which was reported Type I was the common.

The commonest lip pattern found in this study was Type-la and Type-lb. Type la was more prevalent in females and Type lb more in males. This finding was in contrast to the study carried out in India, done by Aman Mital et al. ${ }^{8}$ which reported Type IV lip pattern was most prevalent pattern in males (44\%) and Type I was more in female. Similar finding was seen in study conducted by Sharma et al. ${ }^{9}$ and Verghese et al. ${ }^{10}$ which showed type-IV as predominant type in male and Type 1 in female. The lip print pattern in male and female of Raipur district of Chattisgarh also showed Type la was most common in both male and female in which Type lb was more common in male population and Type la was comparatively more in female. ${ }^{10}$ This variation in prevalence can be explained by the ethnic and racial differences of the several cohort studies.

This study was carried out in a limited sample size. The participants were enrolled using convenient sampling technique. Therefore, our results may not be generalizable to medical students all over Nepal. Further studies with a larger sample size and on a sample which is representative of medical students all over Nepal are required to know the actual prevalence.

\section{CONCLUSIONS}

The lip print pattern Type I is the most common and the variation of lip print pattern is observed between the gender with Type la lip pattern more in female and Type lb lip pattern more in male.

\section{ACKNOWLEGDEMENTS}

We would like to thank the IRC of KMC for providing us with the approval to carry out this research.

Conflict of Interest: None.

\section{REFERENCES}

1. Piccinin MA, Zito PM. Anatomy, Head and Neck, Lips. In: StatPearls [Internet]. Treasure Island (FL): StatPearls
Publishing; 2021 Jan. 2020 Aug 10. [ubMed | Full Text]

2. Sivapathasundharam B, Prakash PA, Sivakumar G. Lip 
prints (Cheiloscopy) Indian J Dent Res. 2001;12:234-7. [PubMed]

3. Kasprzak J. Possibilities of cheiloscopy. Forensic Sci Int. 1990;46:145-51. [Full Text | DOI]

4. Kapoor N, Badiye A. A study of distribution, sex differences and stability of lip print patterns in an Indian population. Saudi J Biol Sci. 2017;24(6):1149-54. [라bMed| Full Text | DOI]

5. Tsuchihashi Y. Studies on personal identification by means of lip prints. Forensic Sci. 1974 Jun;3(3):233-48. [PubMed | Full Text | DOI]

6. Suzuki K, Tsuchihashi Y. A new attempt of personal identification by means of lip print. J Indian Dent Assoc. 1970; 42:8-9. [PubMed I Full Text]

7. Gurung S, Gupta V, Lamichhane A. Prevalence of Type I Lip Print among Medical Students in A Medical College of Nepal. JNMA J Nepal Med Assoc.2019;57(218):221-5. [PubMed | Full Text | DOI]
8. Kumar A, Goel N, Prasad M, Kumar S, Kumari P. Assessment of Lip Print Patterns among the People of Bihar. Journal of Medical Science and Clinical Resequadrant. 2019 Jan;7(1):372-75. [Full Text | DOI]

9. Alzapur A, Nagothu RS, Nalluri HB. Lip prints- A study of its uniqueness among students of MediCiti Medical College. Indian J Clin Anat Physiol. 2017 Jan-Mar;4(1):68-70. [PubMed | Full Text]

10. Verghese AJ, Somasekar M, Umesh BR. A study on lip types among the people of Kerala. Journal of Indian Academy of Forensic Med. 2010;32(1):6-7. [Full Text]

11. Sinha M, Kar A, Mitra M. Extent of lip print pattern variation among people of Raipur, Chattisgarh, India. International Journal of Current Resequadrant. 2016;8(4):28965-70. [Full $\underline{\text { Text] }}$ 